\section{A NEW SCALP HEMOSTAT}

\section{H. J. H. HOEVE, M.D.}

DES MOINES, IOWA

To be satisfactory in all conditions encountered in varying scalps a hemostat must meet the following requirenents:

1. It must compress the entire thickness of the scalp evenly at the incision with sufficient force to control all hemorrhage, but without bruising the tissues.

2. When applied it must never be in the way of the operator.

3. It must facilitate subsequent work on the skull.

4. It must facilitate the introduction of sutures.

In order to meet these requirements I have devised the hemostat here illustrated. The beaks are placerl at right angles to the shanks and present a biting surface of an inch in length, armed with two ridges. 'J'hey are slightly curved from side to side so as to form a half circle when four to six are introduced. The shanks, but especially the inferior one, are sliglstly curved in their longitudinal axis with the concavity downward so as to rest easily on the convexity of the cranium. The upper shank passes distally around the lower shank, which necessitates the pulling instead of the pressing of the hemostat in place during actual

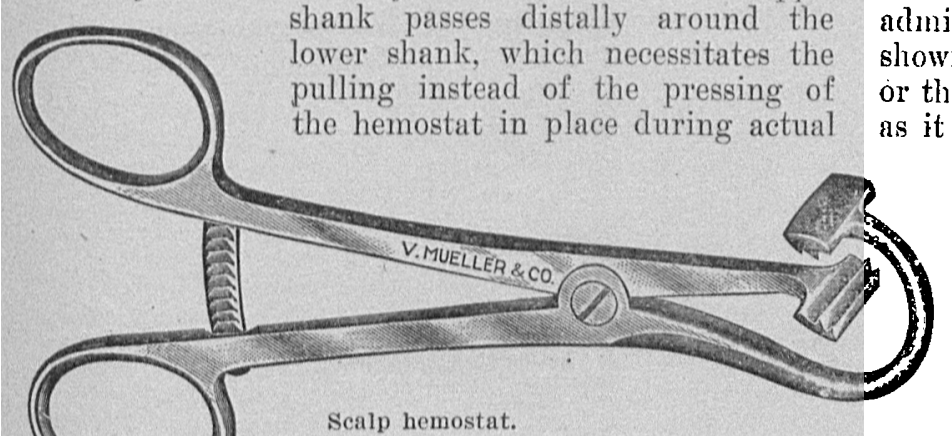

infusions of Atropa mandragora, or mandrake, a member of the group of Solanacea. The nareotic principle of this plant is scopolamin (hyoscin), white a yaralyming effect is produced by another alkaloid, hyoscyamin. Sropolamin or hyosein is found in Hyoscyamus nigrer (Hyoscyamus, U. S. P.), Duboisia myoporoides, Scopola japonica, Atropa belladonna (Belladomna, U. S. T'), and other solanaceous plants. There is evidence that combined poppy and mandrake, lepresenting opium and scopolamin, werc used together three or four hundred year's ago to cause profound sleep and perhaps for anesthetic purposes.

Dr. John Scopoli first described the nction of the alkaloid scopolamin, in $18 \% 1$, and the name scopolamin was first given to it by Jacquin. 'This alkaloid is chemically and physiologically identical with hyoscin, notwithstanding the fact that hyoscin and scopolamin are named as separate alkaloids in the Cnited States and British Pharmacopeias, although now in no others. This alkaloid is not stable when liept in aqueous solutions, and may deteriorate with age even in tablet form. ('onsequently, preparations of scopolamin slould be fresh, and solutions should not be made until just bofore its administration. Deterioration of scopolamin may be shown by a change of color of the tablet, a darkening; or the alkaloid may be contuminated with "apo-atropin," as it is termed. Such tablets are dangerous to use. In other words, only the tablets of reliable and careful firms should be administered to patients in the doses required for anesthesia.

In 1900 , Schmeiderlin published an article slowing that anesthesia could be produced by the use of scopolamin combined with morphin, though more or less of these injections had been used for more than thirty years before.

Scopolamin (hyoscin) has long been used as a hypwork. When the hemostat is introduced the wound margins are turned upward and outward and this facilitates the removal of bone, diploic hemostasis and the introduction of sutures; and, finally, all parts of the instrument are at all times out of the way of the surgeon.

1339 Twentictlı Street.

\section{Therapeutics}

\section{ANESTHESIA AND ANESTHETICS}

(Continued from page 191.5)

\section{SCOPOLAMIN (HYOSCIN) AND MORPIIN AS AN} ANESTHETIC

The production of surgical anesthesia by narcotic ulkaloids dates back, in all probability, nearly two thousand years, and while the earlier uses of these drugs as anesthetics are wrapped in inaccuracies and hyperbole of ancient writings, probably some surgical anesthesia was produced even twenty centuries ago.

Chinese physicians or surgeons in the third century are reported to have produced anesthesia in patients about to be operated on by having them drink infusions of drugs. It is quite likely that the drug most used was the poppy (Papaver somniferum) opium.

Herodotus refers to the Scythian method of producing nareosis by having patients inhale the vapor from burning lemp (cannabis indica, East Indian lemp).

In Europe in early times anesthesia seems to have been produced by the administration of extracts or notic or quieter, for insane patients. This then led to its more genernl use as a hypnotic. and finally to its combined use with morphin as an anesthetic. At first very large doses to produce anesthesia were advised. Very large doses are certainly absolutely unjustifiable. Morphin and scopolamin are synergistic. and each intensifies the hypnotic, soporific and anesthetic properties of the other, morphin acting mostly centrally on the brain (it never being a narcotic to the spinal cord, except in paralyzing doses), while scopolamin acts more or less as an atropin, but also as a marked quieter to the central nervous system and generally as a hypnotic (some patients are made wildy delirious with hyoscin). 'To paralyze the peripheral nerves, in other. words to produce a peripheral anesthesia, large doses - dungerous roses-of scopolamin are required, consequently, scopnlamin alone could not, except by producing dangerous srmptoms, cause anesthesia. Therefore it is only the combination with morphin that can produce or will prodluce such anesthesia with a minimum of danger. Morphin and scopolamin together act similarly to climinish sensation and cause marked drying of the throat and mouth and bronchial tulies. and combined cause drying of the skin and diminished perspirntion.

The most marked antagonistic action of molphin and atropin are on the respiratory (enter. the norphin dulling the respiratory center and the atropin stimulating it. While there may be some slight action as a lespiratory stimulant from scopolamin, its opjosing action to the quicting effect of morphin on the resprirntory center is slight; therefore the danger from the alministration of a large dose of morphin is positively agrravated by scopolamin. Also, scopolamin being a muscle and nerv- 